\title{
BMJ Open Uptake and patient and provider communication modality preferences of virtual visits in primary care: a retrospective cohort study in Canada
}

\author{
Vess Stamenova (D , ${ }^{1}$ Payal Agarwal, ${ }^{1,2}$ Leah Kelley, ${ }^{1}$ Jamie Fujioka, ${ }^{1}$ \\ Megan Nguyen, ${ }^{1,3}$ Michelle Phung, ${ }^{1}$ Ivy Wong, ${ }^{1}$ Nike Onabajo, ${ }^{1}$ R Sacha Bhatia,,${ }^{1,4}$ \\ Onil Bhattacharyya ${ }^{1,2}$
}

To cite: Stamenova V, Agarwal P, Kelley L, et al. Uptake and patient and provider communication modality preferences of virtual visits in primary care: a retrospective cohort study in Canada. BMJ Open 2020;10:e037064. doi:10.1136/ bmjopen-2020-037064

- Prepublication history and additional material for this paper are available online. To view these files, please visit the journal online (http://dx.doi. org/10.1136/bmjopen-2020037064).

Received 16 January 2020

Revised 19 March 2020 Accepted 12 May 2020

Check for updates

(C) Author(s) (or their employer(s)) 2020. Re-use permitted under CC BY-NC. No commercial re-use. See rights and permissions. Published by BMJ.

${ }^{1}$ Institute for Health Systems Solutions and Virtual Care, Women's College Hospital, Toronto, Ontario, Canada ${ }^{2}$ Department of Family and Community Medicine, University of Toronto, Toronto, Ontario, Canada

${ }^{3}$ Department of Public Health Sciences, University of Toronto, Toronto, Ontario, Canada

${ }^{4}$ Department of Medicine, University of Toronto, Toronto, ON, Canada

Correspondence to Dr Vess Stamenova; vess.stamenova@wchospital.ca

\section{ABSTRACT}

Objectives To evaluate the uptake of a platform for virtual visits in primary care, examine patient and physician preferences for virtual communication methods and report on characteristics of visits and patients experience of care. Design A retrospective cohort study.

Setting Primary care practices within five regions in Ontario, Canada after 18 months of access to virtual care services.

Participants 326 primary care providers and 14291 registered patients.

Interventions Providers used a platform that allowed them to connect with their patients through synchronous (audio/video) and/or asynchronous (secure messaging) communication.

Main outcome measures User-level data from the platforms including patient demographics, practice characteristics, communication modality used, visit characteristics and patients' satisfaction.

Results Among the participants, $44 \%$ of registered patients and $60 \%$ of registered providers used the platform at least once. Among patient users, $51 \%$ completed at least one virtual visit. The majority of virtual visits (94\%) involved secure messaging. The most common patient requests were for medication prescriptions (24\%) and follow-up from previous appointment (22\%). The most common provider request was to follow-up on test results $(59 \%)$. Providers indicated that $81 \%$ of virtual visits required no follow-up for that issue and $99 \%$ of patients reported that they would use virtual care services again. Conclusions While there are a growing number of primary care video visit services, our study found that both patients and providers in rostered practices prefer secure messaging over video. Despite fears that virtual visits would be overused by patients, when patients connected with their own primary care provider, many virtual visits appeared to replace in-person visits, and patients did not overwhelm physicians with requests. This approach may improve access and continuity in primary care.

\section{INTRODUCTION}

Timely access to primary care is limited in Canada and in other high income countries, with only $37 \%$ of Canadians reporting that
Strengths and limitations of this study

- This study is the largest evaluation of virtual care within primary care in Canada.

- The study included synchronous (audio/video) and asynchronous (secure messaging) communication to examine physician and patient preference with respect to communication modality.

- Virtual care implementation engaged primary care providers in independent community practices.

- Providers interacted with their own patients, preserving continuity of care.

- Variability on how patients were invited in addition to lack of detailed data on demographic, health and socioeconomic status do not provide insights into equity challenges surrounding virtual care.

they can see their regular provider on the same day. ${ }^{12}$ There is a growing interest in using virtual visits to improve patient access. ${ }^{1}$ Private companies have started to offer virtual visits, which raises concerns that this could undermine continuity of care. ${ }^{2}$ Many see video visits as the most natural replacement of in-person visits, as both audio and visual cues are present. ${ }^{34}$ Video, alongside phone visits, are synchronous communication modalities that require both the patient and the physician engaged at the same time. Asynchronous visits include 'secure messaging' (usually through a secure web-based messaging platform) and emailing; they offer flexibility with responding to messages whenever and wherever the provider or patient wishes.

Despite the growing interest in virtual visits, their use in primary care is very limited in Canada and abroad. ${ }^{4-6}$ While many primary care practices have managed to incorporate email or secure messaging, in a survey of 11 countries Canada ranked last, with only $22 \%$ of practices reporting that they use email for 
patient communication. ${ }^{7}$ Canada ranked fourth (at 16\%) when it came to video visits in primary care, possibly due to the fact that reimbursement for these visits has been available in only one of our provinces since 2012. Overall, video visits were marginal in most countries, and only 9\% of primary care respondents from the UK indicated having used it. A relatively recent survey across general practitioner practices in the UK indicated that $53 \%$ of respondents had no plans to use asynchronous (email or secure messaging) communication, and $86 \%$ had no plans to use video for virtual visits. ${ }^{5}$

Most evaluations to date have focused on examining either video ${ }^{34689}$ or secure messaging, ${ }^{1011}$ but few have examined the patients' and providers' preferences of one over the other. The Canadian province of Ontario implemented a pilot of virtual visits in primary care, where physicians were given access to a platform with options for synchronous (video or audio) and asynchronous secure messaging with their own patients. The purpose of the pilot was to evaluate the uptake of a platform for virtual visits in primary care, examine patient and physician preferences for virtual communication methods and report on characteristics of visits and patients experience of care.

\section{METHODS}

\section{Study design}

This is a retrospective observational study.

\section{Study setting}

The Enhanced Access to Primary Care initiative is a pilot project implemented by the Ontario Telemedicine Network, the provincial lead agency for telemedicine, and it is funded by the Ontario Ministry of Health. The project's goal was to explore how virtual care can be implemented in the province of Ontario and the project was a first step towards integrating virtual care services in primary care. Healthcare in Canada is publicly funded. Primary care physicians in Ontario work as independent contractors with various types of payment models, the most common of which are fee-for-service, capitation and mixed models. The pilot project provided primary care providers from five Ontario health regions (including urban, suburban and rural areas) access to a virtual care platform and allowed them to bill for virtual visits. In Canada, aside from one province (British Columbia), primary care physicians currently cannot bill for virtual visits. Primary care providers were provided with a brief overview of the platform by implementation team representatives. Providers could complete visits in one or more of the following communication modalities: secure messaging, audio or video. The project was launched in September 2017, and we reported on data collected until 15 February 2019. The authors were engaged as a third party evaluator to explore the feasibility and value of using virtual visits in primary care.

\section{Participants}

Physicians, nurse practitioners and administrative staff affiliated with participating primary care providers could register on the virtual communication platform. Providers could only enrol patients with whom they had a pre-existing relationship, which in most cases meant they were rostered to the practice. Primary care providers decided how many and which patients they would invite to register for virtual visits.

\section{Intervention}

Two technology companies (Novari Health, Kingston, Ontario, Canada, https://www.novarihealth.com/evisittelemedicine/ and Think Research, Toronto, Ontario, Canada, https://www.thinkresearch.com/ca/programs/ evisit-primary-care/) co-designed with the Ontario Telemedicine Network and participating pilot primary care providers digital platforms that allowed patients to connect to physicians. Local regional health authorities decided which platform will be used in their region. The Think Research platform was used in one region, while the rest chose the Novari platform. Patients could request visits to be completed through secure messaging, audio and/or video. Patients were instructed that the platform is not to be used for urgent care services, but no general guidance was provided in terms of what is suitable for a virtual care visit versus an in-person visit. It was up to the provider to decide what type of additional instructions they want to give each patient on offering them access to virtual care services. Once a request from a patient was sent, the primary care provider receives a notification (on the platform and through email) that a request was made. The primary care provider had to log into the platform to see the details of the request and the preferred communication modality by the patient, but they could respond to the patient through any of the three modalities offered. Providers were asked to respond within 2 business days of the initiation of a visit by the patient. While some recommendations were made by the implementation team members, it was up to the provider to decide how they will incorporate the virtual visits into their workflow.

Both platforms were developed with this pilot project in mind and further product development and improvements were made throughout the evaluation period. The functionalities of the platforms were very similar, with the notable difference that the Think Research platform allowed patients or physicians to request visits (a functionality requested by the local doctors in the region where this platform was used), while only patients could request visits on the Novari platform for most of the evaluation period.

Patients had free access to the platform and accessed it initially through a website link that was emailed to them from the primary care practice. Subsequently, patients could access the platform by visiting the website. No training was provided to patients to use the platform. Patients were advised that they will receive a response within 2 business days of their request. 
Four different billing codes were created for this implementation: a minor or an intermediate assessment for audio or secure messaging and a minor or intermediate assessment for video visits. Physicians were paid less than their regular face-to-face visit fees for audio/secure messaging visits $(\mathrm{CAD} \$ 15$ per visit for minor assessment and CAD $\$ 21.70$ per visit for intermediate assessment). Effectively, intermediate audio/secure messaging visits were billed on par with minor in-person visits. Video visits were paid on par with provincial billing codes for in-person visits. Physicians who were in capitation models were paid 'shadow billing' ( $15 \%$ of the full fee).

\section{Data collection}

De-identified user-level data was collected from both platforms. The nature of the data collected was determined by the vendors and the organisation implementing the technology in the province. The data included patients' age and gender, practice type, communication modality used, visit characteristics (number of messages sent or video sessions completed), timestamps of when visits were requested and completed, reason for the visit and visit resolution type. The two databases were consolidated where they had overlapping variables and analysis was conducted on the combined data set. Some categorical variables in the data were re-coded so that they could be consolidated into one (see online supplementary for details).

After each virtual visit, patients were invited to complete a short questionnaire on the platform. Three questions overlapped across the two platforms: 'How was your experience compared with an in-person visit?', 'Would you use eVisits again?' and 'What would you have done if you did not have access to Virtual Visits?'

\section{Statistical methods}

The data were analysed using RStudio, V.1.1.463. Data distributions were checked for normality and outliers. Non-normally distributed data or data with heterogeneous variability across groups used non-parametric tests. Missing data were excluded from analyses.

\section{Patient and public involvement}

Patients and the public were not involved in the design or analysis of the study. However, patients were able to provide feedback related to ongoing product enhancements, some of which were implemented during the evaluation phase. As we did not have direct contact with patients, we were unable to offer them access to the results of the study, but we plan on publishing in open access so that interested patients can access the results of the study.

\section{RESULTS}

\section{Participants}

Patients

Between 1 September 2017 and 15 February 2019, 30 753 patients were invited to register for the service by

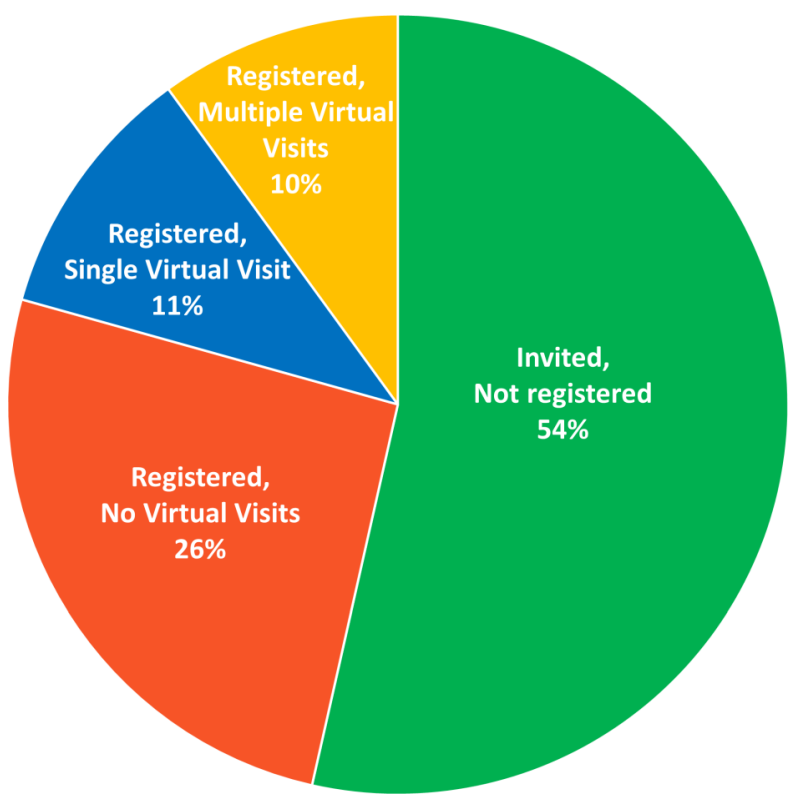

Figure 1 Breakdown of total invited patients $(n=30753)$ according to engagement with the platform.

participating primary care providers (figure 1 ). Of note, 14291 patients registered, and 14317 virtual visits were completed.

The mean age of patient users was 44 (SD 18) (see online supplementary for details about the age variable). Those in their 20s and 30s were more likely to register when invited $(\mathrm{p}<0.001)$, but there was representation from all age categories (figure 2). Women were more likely to register when invited than men $(\mathrm{p}<0.001)$ and $69 \%$ of users $(n=4356 / 6355)$ were women.

\section{Providers}

Among the providers who were registered to use the platform, 60\% ( $\mathrm{n}=194 / 326)$ became users (ie, they had at least one completed virtual visit). With respect to funding models, $74 \%$ of these providers $(\mathrm{n}=144 / 194)$ were in blended capitation models, $25 \%(n=49 / 194)$ of providers were in a fee-for-service model and $1 \%$ in a salaried model.

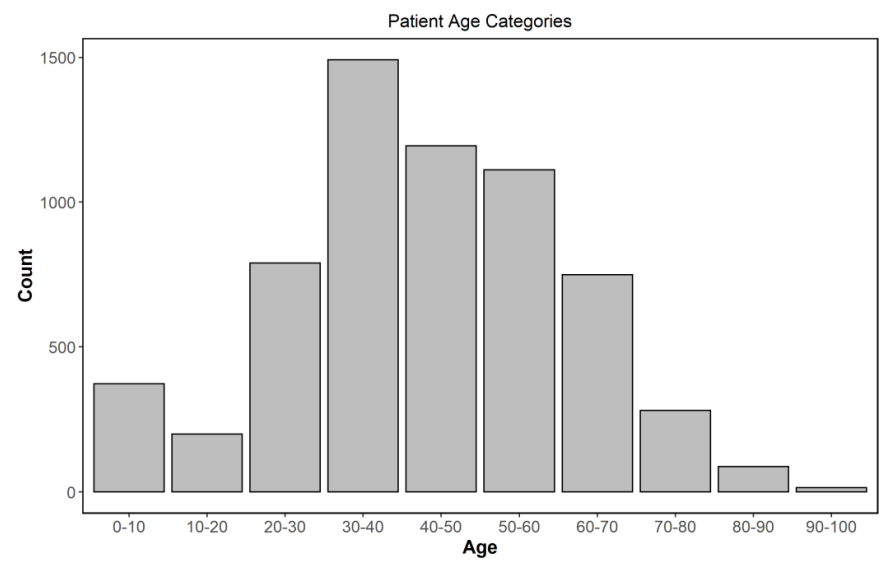

Figure 2 Patient age categories across registered patients $(n=14291)$. 
Table 1 Characteristics of patient user types

\begin{tabular}{lllll}
\hline & Definition & $\mathbf{n}$ & Age & Days to 1st visit \\
\hline Low patient user & $<0.47$ visits/month & 3074 & 45.4 & $58.2(61.8)$ \\
Moderate patient user & $\geq 0.47$ visits/month & 2504 & 43.6 & $22.2(29.9)$ \\
High patient user & $\geq 1.96$ visits/month & 531 & 44.5 & $5.2(10.1)$ \\
\hline
\end{tabular}

\section{Platform use}

Patients

Over the duration of the trial, $44 \%$ of registered patients completed at least one visit. Out of those with at least one visit, $52 \%(n=3278)$ had only a single visit. Across all patients, they completed 0.56 visits per month (SD 0.42). We classified patients as low, moderate or high users based on their monthly visit rate. The cut-off between low and moderate patient users was the median monthly use rate ( 0.47 visits / month), while the cut-off between moderate and high patient users was the lowest classified outlier (1.96 visits/month) (table 1$)$.

The low patient user group was significantly older by about 2 years than the moderate patient user group $(\mathrm{p}<0.001)$, and no other pairwise differences were observed. There was also a significant difference among the patient user groups on the number of days between registration and first visit $(\mathrm{p}<0.001)$ with significant differences across all three pairs $(\mathrm{p}<0.001)$ (table 1$)$.

\section{Providers}

Providers responded to 14317 virtual visit requests. The median time it took for the providers to have their first visit after registration was 28.5 days (median absolute deviation 30.4).

There was a large variability in number of virtual visits among providers with monthly visit rates of $0.1-181.3$. The average number of requested virtual visits per month per provider was 9.58 (SD 10.1), after outliers were removed ( $>1.5$ times of the IQR). Providers were classified as a low, moderate or high user based on the virtual visit rate they had (table 2). The median (6.74) and the outlier border (44.68) defined group assignment. All three group pairs were significantly different from each other on number of registered patients $(\mathrm{p}<0.04)$ and there were no differences in distribution of provider types (capitation vs feefor-service) among the three provider user levels.

\section{Virtual visit characteristics}

\section{Completed virtual visits}

For the duration of the evaluation period, 14317 virtual visits were requested. Within the platform that allowed physicians to request virtual visits, $26.4 \%$ (1741 out of 6584) of visits were requested by physicians (as opposed to patients) (table 3 ).

\section{Communication modality}

\section{Requested communication modality}

When a person initiates a virtual visit, they could indicate the modality in which they prefer the visit to be completed. After excluding virtual visits where multiple modalities were requested (which was possible on one of the platforms), $82 \%$ (out of 13 174) of virtual visits were requested to be completed through secure messaging (figure 3).

\section{Communication modality used}

Across the two platforms, 94\% of virtual visits involved secure messaging (including visits with multiple modalities) (figure 4). On the Novari platform alone, only 17 visits out of $7545(<0.01 \%)$ occurred through videos alone and 196 visits (3\%) occurred through a mix of synchronous (video) and asynchronous communication. Furthermore, $8 \%$ of the visits did not have an associated video or secure messaging communication, and therefore they must have occurred by phone. The median number of audio/video interactions per visit was 1 (range 1-12). A single audio/video interaction was used in $70 \%$ of the synchronous visits and $16 \%$ included two audio/video interactions. We were unable to obtain the number of synchronous visits from the other platform.

Length and time of day of visits

Out of 12895 completed visits, $58 \%$ of the visits were created and $71 \%$ were completed outside typical office hours (08:00 to 17:00), suggesting that at this stage most

Table 2 Provider characteristics per user type

\begin{tabular}{|c|c|c|c|c|c|}
\hline & Visits/ month & $\mathbf{n}$ & $\begin{array}{l}\text { Days since 1st visit, } \\
\text { mean (SD) } p=0.16\end{array}$ & $\begin{array}{l}\text { Number of registered } \\
\text { patients median } \\
\text { (MAD) } \\
\mathrm{p}<0.001\end{array}$ & $\begin{array}{l}\text { Capitation/ } \\
\text { FFS } \\
\mathrm{p}=0.079\end{array}$ \\
\hline Low provider user & $<6.74$ & 95 & $173.49(126.52)$ & $15(14.8)$ & $74 / 20$ \\
\hline Moderate provider user & $\geq 6.74$ & 78 & $128.13(96.74)$ & $84(53.4)$ & $56 / 21$ \\
\hline High provider user & $\geq 44.68$ & 17 & $136.06(96.14)$ & 232 (195.7) & $9 / 8$ \\
\hline
\end{tabular}

FFS, fee-for-service; MAD, median absolute deviation. 
Table 3 Visit outcomes as defined by physicians at the end of a visit

\begin{tabular}{|c|c|c|}
\hline Visit outcome & $\begin{array}{l}\text { Number } \\
\text { of visits }\end{array}$ & $\begin{array}{l}\% \\
(/ 14 \\
317)\end{array}$ \\
\hline $\begin{array}{l}\text { Successfully completed visit; no follow- } \\
\text { up needed }\end{array}$ & 8197 & 57.3 \\
\hline $\begin{array}{l}\text { Successfully completed visit; patient to } \\
\text { follow-up if needed }\end{array}$ & 3551 & 24.8 \\
\hline $\begin{array}{l}\text { Incomplete visit; patient advised to come } \\
\text { in-person }\end{array}$ & 807 & 5.6 \\
\hline Cancelled visit & 542 & 3.8 \\
\hline Active visit & 444 & 3.1 \\
\hline Blank & 420 & 2.9 \\
\hline Incomplete; tech issues & 157 & 1.1 \\
\hline Incomplete; no response from patient & 110 & 0.8 \\
\hline $\begin{array}{l}\text { Incomplete; patient advised to go to } \\
\text { emergency department }\end{array}$ & 54 & 0.4 \\
\hline $\begin{array}{l}\text { Incomplete; patient advised to go to } \\
\text { urgent care clinic }\end{array}$ & 33 & 0.2 \\
\hline Incomplete; other & 2 & 0.0 \\
\hline
\end{tabular}

providers had not incorporated virtual visits into their regular workflow. The average duration of a visit from the time it was requested to the time it was closed was 1.46 days $(\mathrm{SD}=1.7)$ after outliers were removed (duration $<7.24$ days $)$.

Across the two platforms ( $\mathrm{n}=11728$ visits), "new health request' (34\%) and 'ongoing (chronic) health concern' $(29 \%)$ were the two most common reasons for virtual visits. Table 4 provides details on reasons for visit across one of the platforms. When restricting to those two reasons $(\mathrm{n}=7062)$, high user patients were more likely

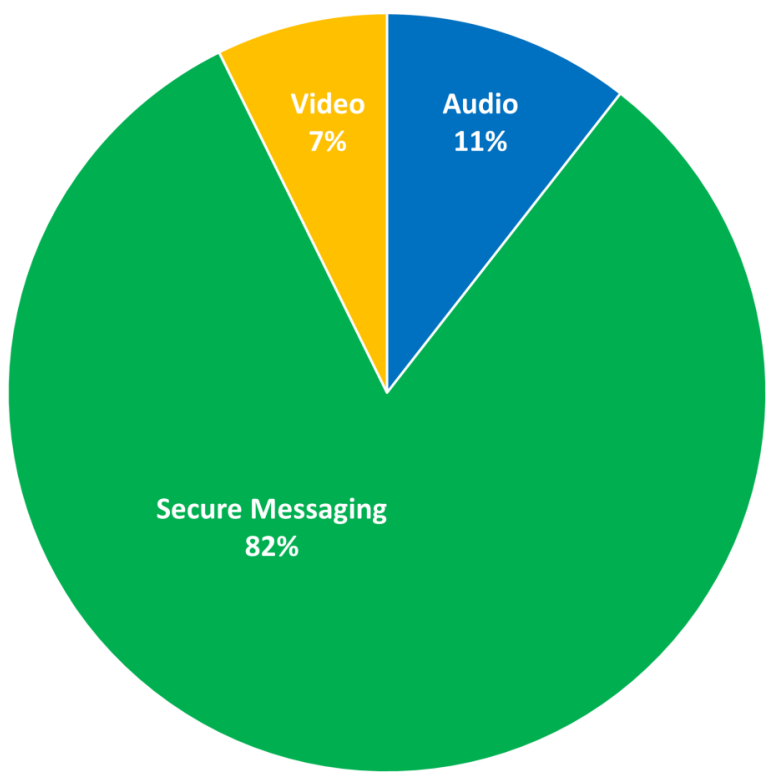

Figure 3 Preferred virtual visit modality at time of virtual visit request $(n=13$ 174).

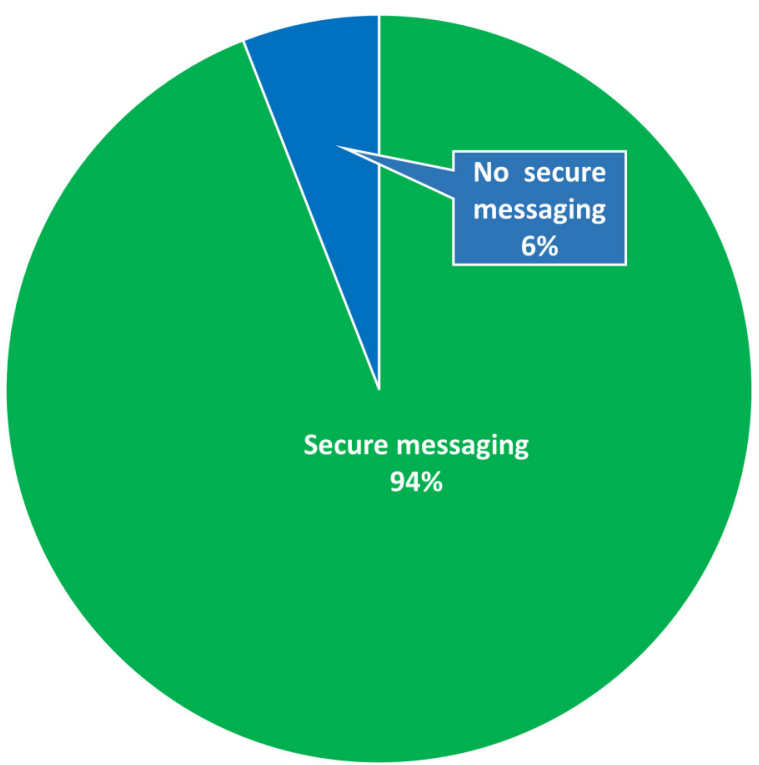

Figure 4 Virtual visits that used secure messaging $(n=13$ 530).

to request visits for chronic conditions than were low user patients, while low user patients were more likely to request visits for new health conditions $(\mathrm{p}<0.001)$.

Table 4 Reasons for virtual visit requests by patients and providers in one of the platforms (think research)

\begin{tabular}{|c|c|c|c|c|}
\hline \multirow{3}{*}{$\begin{array}{l}\text { Reason for visit } \\
\text { request }\end{array}$} & \multicolumn{4}{|c|}{ Requested by } \\
\hline & \multicolumn{2}{|c|}{ Patient } & \multicolumn{2}{|c|}{ Physician } \\
\hline & $\mathbf{n}$ & $\%$ & $\mathbf{n}$ & $\%$ \\
\hline $\begin{array}{l}\text { Request for } \\
\text { medication } \\
\text { prescription }\end{array}$ & 915 & 24.0 & - & - \\
\hline $\begin{array}{l}\text { Follow-up to } \\
\text { a previous } \\
\text { appointment }\end{array}$ & 838 & 22.0 & 157 & 11.0 \\
\hline Other & 641 & 16.8 & 162 & 11.4 \\
\hline $\begin{array}{l}\text { New health } \\
\text { request }\end{array}$ & 544 & 14.3 & - & - \\
\hline $\begin{array}{l}\text { Diagnostic test } \\
\text { results }\end{array}$ & 463 & 12.1 & - & - \\
\hline $\begin{array}{l}\text { Ongoing (chronic) } \\
\text { health concern }\end{array}$ & 406 & 10.7 & - & - \\
\hline $\begin{array}{l}\text { Test results follow- } \\
\text { up }\end{array}$ & - & - & 841 & 59.1 \\
\hline $\begin{array}{l}\text { Discussion about } \\
\text { existing condition }\end{array}$ & - & - & 206 & 14.5 \\
\hline $\begin{array}{l}\text { Discuss } \\
\text { medication }\end{array}$ & - & - & 54 & 3.8 \\
\hline $\begin{array}{l}\text { Postdischarge } \\
\text { follow-up }\end{array}$ & 0 & 0 & 4 & 0.3 \\
\hline \# total cases & 3807 & & 1424 & \\
\hline
\end{tabular}

Some categories were not available as option for either patients or providers and are indicated as '-'. 


\section{Patient survey responses}

\section{Patients' satisfaction}

The majority of patients $(87 \%, \mathrm{n}=1495 / 1716)$ indicated that virtual visits were similar quality as in-person visits, $12 \%$ indicated that it was better and $1 \%$ indicated that it was worse. In addition, 99\% ( $n=1460 / 1474)$ indicated that they would use virtual visits again.

\section{Alternatives to virtual visits}

When patients were asked what they would have done if they did not have access to virtual visits, $64 \%$ $(n=1123 / 1743)$ responded that they would have gone for an in-person visit and 3\% indicated that they would have called their physician (option available only on one of the platforms, see online supplementary for details), $8 \%$ said they would have gone to a walk-in clinic, $2 \%$ said they would have gone to the emergency department, $9 \%$ indicated 'other', $9 \%$ listed multiple alternative options and $5 \%$ indicated that they would have done nothing.

\section{DISCUSSION}

This evaluation of 14317 virtual primary care visits, the largest known study of its kind in Canada, shows two main findings. First, when given an option of choosing synchronous (video or audio) versus asynchronous (secure messaging) communication, both patients and physicians overwhelmingly choose asynchronous communication (secure messaging). Second, when patients use virtual visits to connect with their own physician, they use the service only occasionally, and most virtual visits do not require an in-person follow-up.

\section{Strengths and limitations of the study}

One of the main strengths of this study is that it provides evidence on the use of virtual visits in independent community primary care practices. As such, it generates insight into what a large-scale implementation may look like in a system where patients do not pay for virtual visits, they connect with their own physicians and they can request visits for any non-urgent issue. Another strength is that the platforms allowed for both synchronous (audio/ video) and asynchronous (secure messaging) communication, allowing us to examine both physicians' and patients' communication modality preferences.

One limitation is the regional variability in the ways physicians were recruited, and lack of data on what type of physicians joined and how many refused. Patients' invitation to virtual care was also entirely dependent on the physician's discretion, which may have resulted in a patient sample reflecting physician's biases as to who is suitable for virtual care. More than half of the invited patients did not register and as such it is not clear how generalisable the findings are to the entire patient population. It is very likely that the demographic, socioeconomic and health characteristics of patients who did not elect to use virtual care are distinct from those who chose to participate and future studies should examine these differences.
The programme and the technology continued to evolve throughout the implementation period, and these results are representative of the first 16 months of use which may be different from a more mature stage of adoption. Finally, neither communication platforms were integrated into the electronic medical record (EMR) (aside from a report sent to the providers) that may have reduced its adoption among some physician users.

\section{Comparison with other studies Communication modality}

While there are a number of cohort studies that have reported on the use of virtual care within primary care practices, as far as we are aware, there are no studies to date which report on patients' and providers' preferences regarding communication modality. Most studies offer patients either video only ${ }^{612-14}$ or secure messaging only, ${ }^{15-19}$ and the few that offered both ${ }^{20}$ did not report on patients' preferences of one over the other. Even though video visits seem like the best substitute for in-person visits, ${ }^{34}$ our study indicates that both patients and primary care providers preferred secure messaging over video communication. Previous studies have reported that secure messaging is seen to be convenient and fits with patients' and physicians' schedules, and it provides physicians with time to review the patient's case. ${ }^{22}$ Additional qualitative data from interviews with patient and provider users were collected in the context of this study and will be reported in detail separately. ${ }^{23}$ Briefly, the feedback from both patients and providers was that they preferred the convenience of asynchronous messaging (being able to respond when they can). Additional benefits included more time to think about questions and responses, as well as having a written record of the visit. ${ }^{24}$

We should also note that video communication also requires higher internet speeds and ideally home internet access. Given a significant digital divide in Canada resulting in poor internet access for people with lower income and education, immigrants, older adults and those living in rural settings, ${ }^{25}$ future studies should explore how these factors affect virtual care use and communication modality selection. Literacy levels will also be especially important for text communication, as low literacy levels can impact patients' ability to use this medium and there are estimates that $42 \%$ of Canadians between the ages of 15 and 65 fail to achieve high school level literacy. ${ }^{26}$

From this study, we know that younger patients were more likely to register for virtual care services. More detailed demographic, health and socioeconomic data on a subsample of patients were also collected from a subsample of patients and will be soon reported. ${ }^{23}$

\section{Fear of high patient demand}

Despite common fears that patients will overwhelm physicians with virtual visit requests, ${ }^{22} 2728$ the overall number of requests was modest. Most patients who used virtual care only had a single virtual visit for the duration of the trial. In this implementation, $44 \%$ of registered patients had at 
least one visit, rates which are similar to those reported in other studies $\left(51 \%^{13}\right.$ and $\left.52 \%^{15}{ }^{16}\right)$. Furthermore, $51 \%$ of active patient users (those with at least one visit) completed only a single visit. This is consistent with other studies, which have shown that $65 \%-86 \%$ of patients have only a single visit. ${ }^{131529}$ Other studies have also reported $1.2-2.4$ visits per year per patient user. ${ }^{18}{ }^{30}$ In our study, physicians completed 10 virtual visits per month, with an average of 2.7 messages per virtual visit. The majority of visits were created outside of work hours, which is likely influenced by patient preference, especially for those who work. Furthermore, given the low volume of visits, providers completed most visits outside regular office hours, but that is expected to change if volumes become higher. Failure to incorporate virtual visits into regular office hours as the use of virtual care grows may have a negative impact on providers' workloads and successful adoption of virtual care services. While $58 \%$ of visits were generated out of office hours, which may reflect patient preference, physicians could have completed these within office hours as per the terms of the service.

\section{Do virtual visits replace in-person visits?}

The literature on whether virtual visits can replace in-person visits is still equivocal. The percentage of virtual visits that require follow-up varies significantly across studies, ranging from no differences in follow-up rates ${ }^{31}$ to up to $88 \%$ of virtual visits requiring an in-person visit. ${ }^{152} 32$ In our study, physicians reported that asynchronous communication was sufficient for $81 \%$ of the visits, in that they required no additional follow-up. Physicians only advised patients to go for an in-person visit following $5.6 \%$ of the virtual visit requests. Differences in primary care models, patient populations, methods of determining follow-up rates (eg, self-report vs billing data) and differences in the examined postimplementation intervals, all likely contributed to the variability existing in the literature.

\section{Public policy implications}

Many countries are moving towards incorporating virtual visits in primary care. ${ }^{6} 2133$ Many jurisdictions have been focusing on developing technologies that will allow physicians and patients to connect virtually through video, ${ }^{34}$ and there have been large investments in private sector companies that provide video visit services in Canada ${ }^{35}$ and the UK. ${ }^{36}$ However, this study demonstrates that when virtual care is used by primary care providers with their own patients, both patients and physicians prefer asynchronous communication (secure messaging) over synchronous (audio/video) communication. Given the lower cost and ease of implementation (eg, many EMR systems already offer secure messaging), ensuring that physicians have the means and billing options to provide asynchronous messaging may be a necessary first step before focusing on video visits as some have suggested. ${ }^{34}$ In this implementation, patients most often messaged their providers to request prescription renewals and to follow-up on previous appointments. In the context of lower billing rates for secure messaging or in the context of platforms with prescription renewal or results follow-up functionalities that do not even engage the physician ( models have the potential to result in reductions in avoidable in-person visits.

While the literature on various virtual care implementations in primary care practice is growing, it is important to consider the healthcare system in which these virtual care models are introduced. For example, one should consider whether patients are required to pay for virtual visits, ${ }^{132}$ if they are connecting to their own primary care provider ${ }^{18} 29$ and if they are limited to accessing virtual care services only for certain conditions. ${ }^{1417} 2932$ All these factors are likely to affect both patients' and physicians' behaviour. Here, we are reporting on an implementation of virtual care among independent primary care practices where physicians communicated with their own patients; continuity of care was preserved; patients were able to connect with their providers about any non-urgent matters and patients did not pay for virtual visits. Under these circumstances, we found that patient use was modest and $81 \%$ of the visits required no further follow-up. Therefore, policymakers who are designing virtual primary care models in similar settings can be assured more that virtual visits will likely replace a significant portion of face-to-face visits and patients will not misuse the access they were given.

Furthermore, expanding access to publicly funded virtual visits for patients and their own providers is also likely to increase continuity of care and improve equity, which may be reduced by private companies filling gaps in care with stand-alone services.

\section{Future research}

As this evaluation covered only the first 16 months of a pilot project implemented in Ontario, Canada, it is important to re-examine how use has evolved once both providers and patients have had access to the platform for a longer period. Future research should also focus on using administrative data to track the effect of virtual care on in-person primary care utilisation, emergency department visits and hospitalisations, and include control groups. It is also important to explore how various patient levels of in-person primary care use translate into virtual care use. Furthermore, how virtual visits are used to redesign patient flow and what is the appropriate balance of in-person, virtual, synchronous and asynchronous interaction need further exploration. In this study, implementation was still in early stages and many virtual visits were responded to outside regular clinic hours, suggesting that providers had not modified their current workflow to accommodate this type of visit. Interviews with primary care providers exploring workflow integration and physician adoption barriers and facilitators were conducted in the context of this study and will be reported separately. Finally, it is important to conduct such studies within one's own current model of care, as results from other settings may not be directly applicable. 


\section{CONCLUSION}

The potential of virtual care to address primary care access issues is contingent on using appropriate communication modalities and widespread physician adoption of virtual visits. Physicians' concern that virtual visits will add to in-person visits and increase their workload is common across many countries, and it poses a significant barrier. Our study demonstrates that when they have both options, providers and patients use asynchronous messaging more than synchronous video. Also, when patients use virtual visits to communicate with their own physician, they use them appropriately and physicians' requests for in-person follow-up are very low. These findings suggest that providing asynchronous text communication between patients and providers could improve access to primary care, could preserve continuity of care, and can address physician fears about increased workload.

\section{Twitter Vess Stamenova @vess_stamenova}

Acknowledgements We would like to thank all patients and primary care providers who participated in this pilot project and for agreeing to share their information for this study. We would also like to thank the Ontario Telemedicine Network team, including Payam Pakravan, Lency Abraham, Vivian Henderson, Rhonda Wilson, Karen Blackley, Beth Banting and lan Cummins, for their continuous support of our evaluation and for providing invaluable feedback on this manuscript.

Contributors VS, RSB and OB initiated the study. VS had full access to all the data in the study and took responsibility for the integrity of the data and the accuracy of the data analysis. VS drafted the manuscript. VS performed the statistical analysis. All authors (VS, PA, LK, JF, MN, MP, IW, NO, RSB and OB) contributed to the design of the study; the acquisition, analysis and interpretation of data; and the critical revision of the manuscript for important intellectual content. OB supervised the study and is the guarantor.

Funding The Ministry of Health ( $\mathrm{MOH})$ of Ontario, Canada funded the Ontario Telemedicine Network to develop and implement a virtual care model within primary care. The Ontario Telemedicine Network used part of that $\mathrm{MOH}$ funding to engage the authors to conduct an independent evaluation of the pilot project.

\section{Competing interests None declared.}

Patient and public involvement Patients and/or the public were involved in the design, or conduct, or reporting, or dissemination plans of this research. Refer to the Methods section for further details.

\section{Patient consent for publication Not required.}

Ethics approval The study was approved by the Women's College Hospital Research Ethics Board in Toronto, Ontario. Data transfer agreements were signed between organisations and all data transfer conformed to the agreements. All data were de-identified and participants had agreed to share their non-identifying data for research purposes when registering for the platform, but individual written consent was not obtained from each participant.

Provenance and peer review Not commissioned; externally peer reviewed.

Data availability statement No data are available. Unfortunately, we are unable to share data, as we are limited under data sharing agreements that do not allow us to share the vendor data with third parties.

Open access This is an open access article distributed in accordance with the Creative Commons Attribution Non Commercial (CC BY-NC 4.0) license, which permits others to distribute, remix, adapt, build upon this work non-commercially, and license their derivative works on different terms, provided the original work is properly cited, appropriate credit is given, any changes made indicated, and the use is non-commercial. See: http://creativecommons.org/licenses/by-nc/4.0/.

\section{ORCID iD}

Vess Stamenova http://orcid.org/0000-0003-3252-7766
REFERENCES

1 The BMJ. General practice by smartphone. Available: https:// www-bmj-com.myaccess.library.utoronto.ca/content/366/bmj.14713 [Accessed 25 Jul 2019].

2 Glauser W. Virtual care has potential to fragment primary care and disturb continuity of care, warn doctors. CMAJ 2019;191:E1038-9.

3 Randhawa RS, Chandan JS, Thomas T, et al. An exploration of the attitudes and views of general practitioners on the use of video consultations in a primary healthcare setting: a qualitative pilot study. Prim Health Care Res Dev 2019;20:e5.

4 Donaghy E, Atherton H, Hammersley V, et al. Acceptability, benefits, and challenges of video consulting: a qualitative study in primary care. Br J Gen Pract 2019;69:bjgp19X704141:e586-94.

5 Brant $\mathrm{H}$, Atherton $\mathrm{H}$, Ziebland S, et al. Using alternatives to face-toface consultations: a survey of prevalence and attitudes in general practice. Br J Gen Pract 2016;66:e460-6.

6 McGrail KM, Ahuja MA, Leaver CA. Virtual visits and patient-centered care: results of a patient survey and observational study. J Med Internet Res 2017;19:e177.

7 Doty MM, Tikkanen R, Shah A, et al. Primary care physicians' role in coordinating medical and health-related social needs in eleven countries. Health Aff 2020;39:115-23.

8 Cheung L, Leung TI, Ding VY, et al. Healthcare service utilization under a new virtual primary care delivery model. Telemed J E Health 2019;25:551-9.

9 Reed ME, Parikh R, Huang J, et al. Real-Time patient-provider video telemedicine integrated with clinical care. N Engl J Med 2018;379:1478-9.

10 Zhong $X$, Liang M, Sanchez R, et al. On the effect of electronic patient portal on primary care utilization and appointment adherence. BMC Med Inform Decis Mak 2018;18:84.

11 Player M, O'Bryan E, Sederstrom E, et al. Electronic visits for common acute conditions: evaluation of a recently established program. Health Aff 2018;37:2024-30.

12 McConnochie KM, Wood NE, Herendeen NE, et al. Acute illness care patterns change with use of telemedicine. Pediatrics 2009;123:e989-95.

13 Shah SJ, Schwamm LH, Cohen AB, et al. Virtual visits partially replaced in-person visits in an ACO-based medical specialty practice. Health Aff 2018;37:2045-51.

14 Shi Z, Mehrotra A, Gidengil CA, et al. Quality of care for acute respiratory infections during direct-to-consumer telemedicine visits for adults. Health Aff 2018;37:2014-23.

15 Adamson SC, Bachman JW. Pilot study of providing online care in a primary care setting. Mayo Clin Proc 2010;85:704-10.

16 Cronin RM, Davis SE, Shenson JA, et al. Growth of secure messaging through a patient portal as a form of outpatient interaction across clinical specialties. Appl Clin Inform 2015;6:288-304.

17 Mehrotra A, Paone S, Martich GD, et al. Characteristics of patients who seek care via eVisits instead of office visits. Telemed J E Health 2013;19:515-9.

18 North F, Crane SJ, Chaudhry R, et al. Impact of patient portal secure messages and electronic visits on adult primary care office visits. Telemed J E Health 2014;20:192-8.

19 Zhong X, Hoonakker P, Bain PA, et al. The impact of e-visits on patient access to primary care. Health Care Manag Sci 2018;21:475-91.

20 Bellon JE, Stevans JM, Cohen SM, et al. Comparing advanced practice providers and physicians as providers of e-Visits. Telemed $\mathrm{J}$ E Health 2015;21:1019-26.

21 Pearl R. Kaiser Permanente Northern California: current experiences with internet, mobile, and video technologies. Health Aff 2014;33:251-7.

22 Hoonakker PLT, Carayon P, Cartmill RS. The impact of secure messaging on workflow in primary care: results of a multiple-case, multiple-method study. Int J Med Inform 2017;100:63-76.

23 Kelly LT, Phung M, Stamenova V, et al. Exploring how virtual primary care visits affect patient burden of treatment. Int $J$ Med Inform:In press.

24 Fujioka J, Nguyen M, Phung M, et al. Re-designing primary care using virtual care: provider perspectives on the clinical utility of virtual visits. Canadian Family Physician:In press.

25 Haight M, Quan-Haase A, Corbett BA. Revisiting the digital divide in Canada: the impact of demographic factors on access to the Internet, level of online activity, and social networking site usage. Inf Commun Soc 2014;17:503-19.

26 Jamieson DG, Canada Lin. Literacy in Canada.. Paediatr Child Health 2006;11:573-4.

27 Carter M, Fletcher E, Sansom A, et al. Feasibility, acceptability and effectiveness of an online alternative to face-to-face consultation 
in general practice: a mixed-methods study of webGP in six Devon practices. BMJ Open 2018;8:e018688.

28 Farr M, Banks J, Edwards HB, et al. Implementing online consultations in primary care: a mixed-method evaluation extending normalisation process theory through service co-production. BMJ Open 2018;8:e019966.

29 Padman R, Shevchik G, Paone S, et al. eVisit: a pilot study of a new kind of healthcare delivery. Stud Health Technol Inform 2010;160:262-6.

30 Tang PC, Black W, Young CY. Proposed criteria for reimbursing eVisits: content analysis of secure patient messages in a personal health record system. AMIA Annu Symp Proc 2006:764-8.

31 Gordon AS, Adamson WC, DeVries AR. Virtual visits for acute, nonurgent care: a claims analysis of episode-level utilization. $J$ Med Internet Res 2017:19:e35.

32 Albert SM, Shevchik GJ, Paone S, et al. Internet-Based medical visit and diagnosis for common medical problems: experience of first user cohort. Telemed J E Health 2011;17:304-8.
33 Roland M. General practice by smartphone. BMJ 2019;366:14713.

34 O'Dowd A, O'Dowd A. Doctors question Hancock's idea of GP video consultations for all. BMJ 2018;362:k3934.

35 BetaKit. Telehealth startup dialogue raises $\$ 40$ million to fuel European expansion, 2019. Available: https://betakit.com/telehealthstartup-dialogue-raises-40-million-to-fuel-european-expansion/ [Accessed 21 Aug 2019].

36 Field M. NHS chatbot app babylon raises $\$ 550 \mathrm{~m}$ with Saudi backing as MP demands inquiry into funding. the telegraph, 2019. Available: https://www.telegraph.co.uk/technology/2019/08/02/nhs-chatbotapp-babylon-raises-550m-help-saudi-backing/ [Accessed 21 Aug 2019].

37 Fagerlund AJ, Holm IM, Zanaboni P. General practitioners' perceptions towards the use of digital health services for citizens in primary care: a qualitative interview study. BMJ Open 2019;9:e028251. 